\title{
FINDINGS OF FACT AND CONCLUSIONS OF LAW IN CASES WHERE JURIES ARE WAIVED
}

\author{
EdSON R. SUNDERLAND*
}

TRIAL by jury is a somewhat complicated process. Two judicial agencies divide the field between them, one dealing with issues of

1 fact and the other with matters of law. But the two proceedings are mutually dependent. The court is required to determine what issues of fact are present in the case and to convey that information to the jury, whereupon it becomes the exclusive duty of the jury to decide those issues. The court is also required to determine what principles of law should control the case, but it is not essential that the jury be informed regarding them unless the jury is to apply the law to the facts. This is a proper but not a necessary jury function, for under our traditional conception of the judicial process either the jury or the court may be permitted to perform it. If the application is to be made by the jury the court must inform it as to what those principles are, while if the court is to make the application the jury must inform the court what facts are to be deemed established. In either event, therefore, one agency must communicate its conclusions to the other.

The technique which the common law developed for securing the necessary co-operation between the judge and jury in this joint proceeding was reasonably convenient and effective. The judge stated to the jury what issues of fact there were in the case. If a special verdict was to be rendered he did this by submitting written questions to be answered in writing by the jury, or by submitting alternative statements of facts, one or the other of which was to be selected and approved by the jury in accordance with its view of the evidence. To the facts so established by the special verdict the judge then applied the law by rendering such a judgment as the law and the facts required.

If the verdict was to be general, the judge orally stated to the jury what principles of law it should apply to the facts which it might find. The jury thereupon made the application by rendering a verdict for one party or the other, as the law and the facts required, without, however, expressly stating what those facts were. The court then rendered judgment in accordance with this verdict.

* Professor of Law and Legal Research, University of Michigan. 
This formal and somewhat elaborate procedure was entirely due to the simultaneous use of two different agencies for dealing with the controversy. If one agency alone, either the jury as in the early days of the common law, or the judge as in the chancery courts, had been authorized to deal with the whole case, these methods for the communication of information between judge and jury would no longer serve any useful purpose in the trial of the case.

When, accordingly, waiver of juries in law actions was authorized, there was no necessity, from the point of view of trial convenience, for retaining any counterpart of the mechanism by which court and jury communicated with each other. By combining both functions in the judge he could proceed directly to decide the case, without, as judge, expressly informing himself, as jury, what legal principles should be employed in reaching a general decision, or as jury, expressly informing himself, as judge, what facts had been found.

\section{LEGISLATION REGARDING FINDINGS}

England and the British dominions, in adminstering non-jury cases at law, completely abandoned all those features of the common law trial which were based upon the division of functions between judge and jury. The English rule simply provides that "The judge shall, at or after the trial, direct judgment to be entered as he shall think right." I No formal statements are required from the judge as to the issues which he considers material or as to the principles of law which he considers controlling. $\mathrm{He}$ is not required, in his capacity as jury to formally make findings of fact, either general or special, to which, in his capacity as judge, he applies the law which he has announced. He merely proceeds, in the informal manner of a chancery judge, to hear the case and decide it. Mr. Odgers describes the whole process in a single sentence: "In non-jury cases he [the judge] gives judgment at the conclusion of counsels' speeches, stating his reasons." 2 Even the reasons are not required, and some of the approved forms do not contain them. ${ }^{3}$ Nothing need be stated by the judge beyond sufficient facts and directions to enable the clerks in the proper department to enter the correct judgment. ${ }^{4}$

This simple method of conducting non-jury trials is followed in a few

$\times$ Order 36 , rule 39 . Similar provisions are found in the dominions: Ontario Jud. Act, rule 55 (I915); Australia, Order 33, rule 22; Queensland, 3 Pub. Gen. Acts rgIr, Rules of Court, Order 39 , rule 37 .

$=$ Odgers, Pleading and Practice, $\$ 339$ ( $x$ xth ed.).

3 Chitty's Forms 445 (I93I); See Ontario Jud. Act I915, Rule 264, n.p. 723.

4 England, Order 36, rule 4I; Order 4I, rule 2; Australia, Order 33, rule 23. 
American states. In three of the New England states: Maine, ${ }^{5}$ Massachusetts, ${ }^{6}$ and Vermont; $;$ two central Atlantic states: Virginia, ${ }^{8}$ and West Virginia; ${ }^{9}$ and three southern states: Florida, ${ }^{\text {Io }}$ Louisiana, ${ }^{\text {II }}$ and Mississippi, ${ }^{x_{2}}$ no special rules or regulations seem to be prescribed for the conduct of non-jury trials. The judges are merely authorized to hear and determine such cases, or the authority to do so is inferred from the existence of the right to waive a jury. In Michigan by court rule adopted in I93 ${ }^{13}{ }^{13}$ and in Mllinois by statute enacted in $1933,{ }^{14}$ the characteristic analogues of the jury trial, namely the separate findings of fact and conclusions of law, have been declared to be unnecessary for any purpose, and in a number of other states, statutes formerly requiring them have been repealed. ${ }^{5}$

But in the great majority of the jurisdictions in this country trials without a jury have been complicated by more or less elaborate requirements for retaining the counterparts of the procedure at common law developed in jury cases.

It was the evident purpose of the New York Practice Commission of I848 to provide a trial procedure in non-jury cases free from every vestige of the common law jury technique. The model before them was the trial in equity. In their first report the Commission discussed the question whether law and equity cases could be tried by a uniform method, and concluded without hesitation that a trial by the court was equally applicable to both. The equity requirement of written testimony, it was pointed out, was a wholly unnecessary and immaterial feature, which could with great advantage be eliminated. So modified, the equity method of trying issues of fact was entirely suitable for jury-waived cases at law. ${ }^{16}$

This theory was embodied in section 267 of the Code of 1849 , which provided, without further elaboration, that "Upon a trial of a question of fact by the court its decision shall be given in writing, and filed with the clerk. . . . Judgment upon the decision shall be entered accordingly."

5 Me. Rev. Stat. 1930, c. 9 r, $\S 26$.

${ }^{6}$ Mass. Ann. L., I933, C. 23r, $\$ 77$.

? Vt. Pub. L., 1933, \& 2069.

8 Va. Code I93o, § 60г 2; see also Bagby's Md. Code r924, art. 75, §§ rog, х33.

9 W.Va. Off. Code I93I, c. 56, art. 6, § Ir. $\quad$ " Dart's La. Prac. Code, § 494 (1932).

xo Fla. Comp. Gen. L. x927, $\$ 4358$. ${ }^{12}$ Miss. Code I930, $\$ \$ 577,580,587$.

${ }_{33}$ Mich. Ct. Rules, rule 37 (I93I and r933).

${ }^{4}$ Civ. Prac. Act 1933, $\$ 64$.

is Some of these statutes are hereinafter referred to.

${ }^{16}$ Field, Speeches, Arguments and Miscellaneous Papers 270. 
The foregoing provision, which is substantially identical with the modern English rule in non-jury cases, if examined by a mind strongly impressed with the common law pattern and determined to retain everything reminiscent of the old procedure not expressly abolished, could perhaps be interpreted as not excluding the use of conclusions of law and findings of fact as substitutes for the court's instructions and the jury's verdict. In an early case Hand, J., observed that the statute was "very obscure in relation to trial by the court," and "unless the decision finds all the facts distinctly traversed .... it will be very difficult for the parties to know and protect their rights in any future suit, and the record must necessarily be imperfect, ...." and he concluded that, by analogy to the former practice, special findings should be made on all the issues. ${ }^{17}$

The reason here given is not convincing, for the common law general verdict, which was the form of verdict ordinarily used, never disclosed the particular facts found and yet it had caused no practical difficulty when it became necessary to establish a prior recovery. The real objection to the simplified practice was perhaps an unconscious professional hostility to a departure from familiar forms. But whatever the explanation, it was not long until an amendment of section 267 found its way into the statutes which largely nullified the purpose of the Field Commission. By this act, passed in I860, it was provided that the decision "shall contain a statement of the facts found, and the conclusions of law separately," and that "judgment upon the decision shall be entered accordingly."

This statute was the forerunner of a vast amount of legislation which, in a majority of the states of this country, imposed upon non-jury trials many of the technical features incident to trials by jury at common law.

The extraordinary amount of variation among American statutes dealing with written findings and conclusions is persuasive evidence of a want of any sound theory of procedural policy upon which they might be supposed to rest. Some require findings of fact but not conclusions of law, while others require both. Some make one or both obligatory in all cases, some require them only when specially requested, and some require them unless they are waived. Some statutes permit either general or special findings, others require all findings to be special, others permit general findings unless one of the parties requests that they be special, or unless one of the parties shall make such request "with a view to excepting to the decision of the court," and others are silent as to their form. Under most statutes findings are equally necessary in law and equity cases, but

${ }_{77}$ Gilchrist v. Stevenson, 7 How. Pr. (N.Y.) 273 (1852). 
some statutes apply only to actions at law. Some make the finding a part of the record, others are silent on the point. ${ }^{x}$

This want of a settled and uniform practice among the several states finds a parallel in the want of continuity in the statutory policy of many of the individual states. Thus, New York required no findings in its Code of 1848 , but in 1860 separate findings of law and fact were made obligatory. In 1895 it was provided that the decision "may state separately the facts found and the conclusions of law." "I9 In I903 obligatory special findings were restored; ${ }^{20}$ in I934 a general finding was made permissive unless the parties stipulated for special findings, ${ }^{25}$ and in 1936 special findings were required but might be either oral or written. ${ }^{22}$

In California findings were required in every case, under the law of $I 85^{1 ; 3}$ in 1866 they were required only if requested by either party;24 and in 1872 they were required in all cases unless expressly waived..$^{25}$

In Colorado it was provided by the Code of 1877 that findings should be made in all cases if required by either party, ${ }^{26}$ but this provision is not found in the Code of 1887 . Nevada required separate findings of law and fact in $\mathrm{I} 86 \mathrm{I},{ }^{27}$ but this was repealed in I9I $5 .{ }^{28} \mathrm{In} \mathrm{New}$ Jersey prior to I9I2 there was no requirement for findings, aside from a general provision that the report or determination of the court should be entered in the minutes, ${ }^{29}$ but in the Practice Act of $\mathrm{rg} 2 \mathrm{r}$ findings were required. ${ }^{30}$ Missis-

${ }^{28}$ The statutes now requiring findings of some kind under some of the conditions here mentioned are the following: Ala. Code I928, § 9500; Ariz. Rev. Code I928, § 38I9; Ark. Civ. Code $1934, \S 364$; Cal. Code Civ. Proc. I93I, §§ 632-34; Conn. Gen. Stat. I930, § 5660; Idaho Code 1932, $\$ \$ 7-302,7-304$; Burns Ind. Stats. I933, §§ 2-2 Ior, 2-2102; Iowa Code 1931, $\S$ II435; Kan. Rev. Stats. $x 923$, §60-292I; Mo. Rev. Stats. I929, § 952; Mason's Minn. Stats. r927, § 93Ix; Mont. Rev. Code I92r, §§ 9366-8; Neb. Comp. Stats. I929, § 20-II27; Nev. Comp. L. $x 929, \S 8783$; N.J. Prac. Act I9I 2 , rules 74, 75; N.Y.L. I936, c. 9I5; N.C. Code I 93 , $\S 569$; N.D. Comp. L. I913, \$§ 7638-40; Throckmorton's Ohio Code I934, § II421-22; Okla. Stats. I93I, § 374; Ore. Code I930, § 2-502; Purdon's Pa. Stats. I93I, tit. I2, § 689; R.I. Gen. L. I923, $\S 49 \mathrm{II} ;$ S.C. Code I932, $\$ 649$; S.D. Comp. L. I929, $\$ \$ 2525^{-27}$; Shannon's Tenn. Code I932, § 88II; Tex. Comp. Stats. 1928, \$§ 2208, 2209; Utah Rev. Stats. I933, §§ I04-26-2, 3; Remington's Wash. Rev. Stats. I932, $\$ \S 367,368$; Wis. Stats. I933, $\$ 270.33$; Wyo. Rev. Stats. I93x, $\$ 889-132 \mathrm{r} ; 28$ U.S.C.A. $\$ 773$ (1934).

I9 Parson's Code 1899 , § Io22 (italics added).

20 Parker's Code r904, § Io22.

${ }^{21}$ Cahill's N.Y. Civ. Prac. Act, $\$ 440 a$ (1934).

22 Id. at $\S 440$, as amended by Laws of 1936 , c. 9r5.

${ }^{23}$ Laws, I85x, second session, pp. $78-79 . \quad{ }^{27}$ Sec. 180.

24 Laws $x 865-6$, p. 844 .

${ }^{28}$ Comp. I. I929, $\$ 8783$, note.

25 Code of $1872, \S 632$.

${ }^{29}$ Comp. L. I9I0, p. 4100, § I54.

${ }^{6} \mathrm{Code}, \S$ I85.

${ }^{30}$ Rule 74. . 
sippi had a provision for findings of fact and law in its Code of $187 \mathrm{I}$, but the revised code of 1880 omitted it. ${ }^{3 \mathrm{I}}$

An examination of the questions which have arisen out of these various provisions for findings will show how troublesome they have been and how little they have contributed toward an efficient administration of justice in the trial courts.

\section{CONCLUSIONS OF LAW}

These correspond to the instructions given by the court to a jury when it renders a general verdict and to the rules which the court applies when it renders judgment upon a special verdict. Most states which require findings of fact also require findings or conclusions of law, though Alabama and Connecticut do not. On the other hand, Maryland requires only conclusions of law. ${ }^{32}$

Requirements for stating both conclusions of law and findings of fact carry the analogy of the jury technique beyond what the common law itself ever contemplated. It was only when the jury rendered a general verdict that formal propositions of law were stated by the court in giving or refusing instructions. When a special verdict was rendered the court was never required to formally spread upon the record the conclusions of law which it chose to apply in rendering judgment upon that verdict.

But in spite of the great extension and mandatory terms of the requirement for conclusions of law, it has become practically a dead letter. To reverse a correct judgment because no conclusions of law were stated or because the court stated wrong conclusions, would be absurd. As the Supreme Court of California said in Haffley v. Maier:

The judgment was right on the undisputed facts, though a wrong reason was given for it. But we do not reverse for what we regard as bad logic, but for what we consider bad law. 33

If it should be held that the court committed error in stating incorrect conclusions of law, yet after a correct judgment has been rendered such error would be without prejudice and ought to be given no consideration.

Thus, in Nelson v. Ferris, the court said:

As the only error set up in the record is the judge's conclusion of law from the facts found, we are only required to consider whether the facts found support the judgment. If they do so, it is not very important to inquire whether the conclusions of law apart from the judgment are correct or not. Unless the plaintiff has been injured by the judgment it will not be disturbed. ${ }^{34}$

${ }^{3 x}$ Code of $1871, \$ 650$; compare Code of 1880 .

${ }^{32}$ Md. Ann. Code 1924, art. 75, § 109.

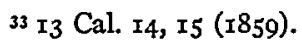

${ }^{34} 30$ Mich. 497,498 (I874). 
In Gathemann v. City of Chicago, ${ }^{35}$ error was assigned on the ground that the propositions of law stated by the trial court were inconsistent but the court said that, conceding such inconsistency, there should be no reversal because the right judgment had been rendered on the established facts. In Rea v. Haffenden, ${ }^{36}$ no conclusions of law whatever were stated but the court refused to reverse, on the ground that the judgment was sustained by the facts and failure to state express conclusions of law was therefore immaterial. So in Gaffney v. Megrath, ${ }^{37}$ the court held that it was its duty, irrespective of the correctness or even of the existence of conclusions of law, to direct such a judgment as the facts warranted.

The formulation and presentation to the court of legal propositions might often be useful for challenging the court's attention to the legal questions involved in the case. But this is a matter of mere trial convenience. If no formal conclusions are employed counsel could bring out the same points in other ways during the trial and argument of the case. Formal legal conclusions and oral suggestions would serve exactly the same purpose in securing a proper judgment, and counsel might well be permitted to make their own choice between the two methods. By attempting to turn a matter of occasional convenience into an inflexible and obligatory requirement of practice, the statutes have complicated, without facilitating, the task of court and counsel in trying non-jury cases, and have multiplied the opportunities for vexatious appeals.

\section{GENERAI FINDINGS OF FACT}

The federal statute permits the judge in his discretion to make either a general or a special finding of facts. The statutes of Alabama, Indiana, Kansas, Kentucky, Missouri, Nebraska, Ohio, Oklahoma, Oregon and Wyoming, expressly permit a general finding unless one of the parties requests special findings. In New Jersey the finding may be general when all the facts are found for the prevailing party.

A general finding is a very simple thing to draw, and introduces no difficulty into the conduct of the trial. But it is as useless as it is simple. A judgment for a party necessarily implies a general finding for that party, and to require a formal general finding in addition to the judgment is quite superfluous. This is apparent from the ease with which the courts are able to supply its place by presumption.

In a number of states the statutes expressly provide that findings may be waived by the parties in the manner therein specified. This is the case

${ }^{35} 263$ IIl. 292, I04 N.E. 1085 (I9I4).

${ }^{36}$ II6 Cal. 596, 48 Pac. 7I6 (I897).

37 II Wash. 456, 39 Pac. 973 (I895). 
in California, Idaho, Montana, North Dakota and South Dakota. A judgment could be sustained under such a waiver only on the theory of an implied general finding for the party for whom the judgment was rendered, and it has been held that in such a case a general finding in support of the judgment will be conclusively presumed..$^{38}$ But the court will go farther still to avoid disturbing a judgment because of an absence of any finding. Where no waiver has in fact taken place, the court will nevertheless presume a waiver, in the absence of an affirmative showing to the contrary in the record, in order to indulge the further presumption of a general finding in favor of the judgment. ${ }^{39}$

In some states no findings are required unless requested by one of the parties. This is the rule in Arizona, Connecticut, Iowa, Nevada, Rhode Island, Tennessee and Texas. If no request is made, and there are no findings, it has been held that the judgment will be sustained by implying a general finding. ${ }^{\circ}$

It would appear, therefore, that general findings of fact like conclusions of law, are purely formal requirements, which serve no substantially useful purpose and ought always to follow as a necessary inference from the judgment itself, but they cause little or no trouble because they are easy to draw and can be supplied by intendment whenever the point is raised. However, they introduce a source of risk into the proceedings by presenting a basis for a possible technical objection to the judgment.

\section{SPECIAI FINDINGS OF FACT}

There is no express authorization of general findings in the statutes of Arizona, Arkansas, California, Connecticut, Idaho, Iowa, Minnesota, Montana, New York, North Carolina, North Dakota, Pennsylvania, South Carolina, South Dakota, Tennessee, Texas, Utah, Washington or Wisconsin, and it is generally assumed, from the wording employed, that the findings are required to be special. Rhode Island expressly requires special findings.

By comparing this list with the list of states previously given in which either kind of finding is permitted, it appears that in about two-thirds of those jurisdictions which recognize the practice, special findings are re-

${ }^{38}$ Rankin v. Newman, I07 Cal. 602, 608, 40 Pac. 1024, 1025, 4I Pac. 304 (I895).

39 Campbell v. Coburn, 77 Cal. 36, 18 Pac. 860 (1888); Squier v. Lowenberg, I Idaho 785 (1880).

${ }^{40}$ Murray v. Osborne, 33 Nev. 267, 277, III Pac. 3r, 33 (xgro); Craig v. Marx, 65 Tex. 649 (I886); Tom Reed Gold Mines Co. v. United Eastern Min. Co., 24 Ariz. 269, 209 Pac. 283 (1922). 
quired in all cases, while in about one-third of them special findings may be required where the parties or the court so elect.

The actively troublesome character of the special finding results largely from two features: (I) it is usually deemed to be a part of the record or judgment roll; and (2) it is held to serve the same purpose, and to be judged by the same standards, as a special verdict. The statutes of Iowa and Washington expressly provide that the finding shall have the effect of a special verdict, but the others are nevertheless construed to intend the same thing without express language to that effect.

There is nothing more technical than a special verdict. It must be sufficient on its face to sustain the judgment, and every fact not stated is deemed to have been found against the party having the burden of proof. An inadvertent omission is as fatal as an actual defect in the case. Even facts not contested at the trial, if formally in issue on the pleadings, must be included, or the party relying upon them will be unable to sustain a judgment.4x Such facts, being outside the actual issues of the trial, are easily overlooked. The facts stated must be only ultimate facts, not evidence or legal conclusions, and as no safe test has ever been devised by which to distinguish between these three kinds of statements, the task of drawing up the verdict is obviously a difficult one. And finally, the facts must be stated in definite, certain and unambiguous terms. The problems involved in framing the special verdict are analogous to those involved in drawing pleadings, and both documents are subject to similar objections. But while the pleadings are subject to attack at a time when defects may still be removed by amendment, a defective special verdict is incurable after the jury is discharged, and the rights of the parties are fixed by it without regard to the actual circumstances of the case. In other words, parties employ special verdicts strictly at their peril. For that reason the special verdict has largely gone out of use. Holdsworth says that the practice of taking a general verdict subject to a special case was due to the difficulty of framing special verdicts, ${ }^{42}$ and common law writers recommended that practice. ${ }^{43}$

If the special finding is to be a part of the judgment roll, the common law requirements regarding the record at once apply, and nothing beyond the facts set out in the findings can be looked to to support the judgment.

${ }_{4 \pi}$ Standard Sewing Machine Co. v. Royal Ins. Co., 20r Pa. St. 645, 5I Atl. 354 (Ig02); Hodges v. Easton, 106 U.S. 408 (I882).

$4^{2}$ I Holdsworth, History of English Law 282-83 (I93I).

${ }^{43}$ I Archbold, Practice 2I6; 2 Bl. Comm. *378; I Burrell, Supreme Court Practice 242; Wyche, Treatise on Practice 169 . 
Numerous decisions hold that the findings are to be considered the sole foundation upon which the judgment rests. ${ }^{44}$

This means that after a party has assumed and surmounted the risk of stating his case in the form of technically good pleadings, he must again incur the risk of translating his proofs into the form of technically good special findings.

All the technical refinements of the special verdict reappear in the special findings, and there are decisions which sustain, as against such a finding, every type of objection which could have been made to a special verdict. Thus, the omission from the finding of any fact in issue is equivalent to a finding that it was not proved, ${ }^{45}$ or will at least prevent the entry of a judgment for the party who relies upon it..$^{6}$ The facts found must be sufficient to support the judgment, as nothing will be taken by intendment. ${ }^{47}$ A judgment cannot rest upon legal conclusions, ${ }^{48}$ nor upon evidentiary facts, ${ }^{49}$ nor upon inconsistent findings, ${ }^{50}$ nor upon findings which are uncertain or ambiguous, ${ }^{5 \mathrm{I}}$ nor upon facts not responsive to the pleadings..$^{52}$ Nor can insufficient special findings be aided by adding a general finding. ${ }^{53}$

Rules of liberal construction, presumptions in favor of the judgment, remand for new trial as a substitute for the injustice of a final judgment on defective findings, or a remand for additional or amended findings as a substitute for an unnecessary new trial, and other doctrines and devices, have been resorted to in mitigation of the harshness of the common law practice relating to special verdicts. But the burden of preparing findings, and many opportunities for attack upon the judgment, still remain in every case where findings are used. In recommending the abolition of

${ }_{44}$ Western Dry Goods Co. v. Hamilton, 86 Wash. 478, I50 Pac. II 7 I (rgr 5 ); O'Blinski v. Kent Circuit Judge, 34 Mich. 62 (1876); Miller v. Barnett, 49 Okla. 508, 153 Pac. 64I (1915).

45 Graham v. State ex rel. Comm'rs, 66 Ind. 386, 394 (1879); James v. West, 67 Ohio St. 28, 49,65 N.E. $\times 56,160$ (1902).

${ }^{6}$ Speegle v. Leese, 5 I Cal. 4I 5 (I876).

47 Hill v. Swihart, 148 Ind. 3I9, 323, 47 N.E. 705, 706 (1897); St. Paul \& Duluth R.R. Co. v. Village of Hinckley, 53 Minn. 398,55 N.W. 560 (I893).

$4^{8}$ Utah Nat. Bank v. Nelson, 38 Utah I69, III Pac. 907 (19I0); Kane v. Rippey, 22 Ore. 299, 29 Pac. 1005 (1892).

49 Pio Pico v. Cuyas, 47 Cal. I74 (I873).

5o Randall v. Hunter, 66 Cal. 5I2, 6 Pac. 33 I (x885); Kountz v. Kountz, I5 S.D. 66; 87 N.W. 523 (Igor).

5x Buchanan v. Milligan, 108 Ind. 433, 9 N.E. 385 (1886); Lesher v. Getman, 28 Minn. 93, 9 N.W. 585 (I88I).

52 Florence Mfg. Co. v. Pacific Exp. Co., 36 Utah 346; 103 Pac. 966 (rgog).

53 Savings \& Loan Society v. Burnett, Io6 Cal. 5I4, 539, 39 Pac. 922, 929 (I895). 
special findings in jury-waived cases the Michigan Procedure Commission said:

It is an opinion widely held by the bar and bench of this state, that the greatest obstacle to the waiver of juries in civil cases is the requirement for special findings. The preparation of findings is burdensome. .... Special findings of fact, when employed, become the foundation for the judgment, and the evidence cannot be looked to as in equity cases. It results from this that after a case has been properly established by proof it will always be jeopardized and may frequently be ruined in the process of transcribing it into the form of findings. 54

The practical question presents itself, whether the burdens incident to this practice are justified by any resulting benefits.

Special verdicts at common law were not originally employed to facilitate trials, but to protect juries from the additional risk of attaint which was involved in dealing with questions of law..$^{55}$ The incidental advantage enjoyed by the parties was due entirely to the fact that the judge, who understood the law better than did the jury, was enabled thereby to apply it himself to the facts, instead of attempting to qualify the jury to apply it.

With the disappearance of the attaint the primary purpose of the special verdict disappeared. The advantage of having the court apply the law remained, and may have tended to increase as the law became more complex and more difficult for juries to understand. But the burden and jeopardy involved in preparing and using the special verdict is by no means counter-balanced by the elimination of the risk that the jury may not understand the law or may not or cannot properly apply it.

Be that as it may, with waiver of the jury, the whole principle employed in the special verdict ceases to have any practical application. Having heard the evidence and found the facts the judge can gain nothing by informing himself in writing regarding what he already knows.

The specific matters in issue may perhaps be brought more effectively to the court's attention by presenting them in the form of written findings. But this can hardly be of great importance in an ordinary trial, for the issues have already been presented, first, by the pleadings, second, by the evidence, and third, by the arguments of counsel, so that a fourth presentation, in the form of proposed findings, would hardly seem necessary. To enjoy whatever advantage there may be, however, in this method of focusing judicial attention on controlling issues, it is not essen-

54 Mich. Ct. Rules, rule 37 n., § Ir (Mich. L. School ed. I93r).

ss Co. Litt., $\S 368$ (Ist Am. fr. Igth London ed. r853); Sunderland, Verdicts, General and Special, 29 Yale L. J. 253 (I920); Morgan, A Brief History of Special Verdicts, 32 Yale L. J. 575 (I923). 
tial to treat a proposal for special findings as the submission of a selfsufficient special verdict. The presentation of one or more questions of fact, to be specifically passed upon by the court, might be authorized as a mere matter of trial convenience, to be availed of in the court's discretion. Such a rule would give the party all the protection needed against judicial oversight, without subjecting the judgment to unnecessary risk. Such appears to be the practice in Massachusetts. In Davis v. Boston Elevated Ry. Co., the court said:

The judge was under no obligation to make any findings of fact. He could not be required to do so by requests presented by the parties or either of them. .... Even in equity, where the practice in this particular is much more liberal than at law, it has been said that such a practice should not be encouraged, for its inevitable result would be to put on trial the magistrate instead of the case. ... This is an action at law. The only obligation of a judge in an action at law is to pass upon pertinent requests for rulings of law seasonably presented and to decide the case. .... Findings of fact not infrequently are made and the reasons of a decision stated for the information of parties and counsel, but that is merely a practice of convenience..$^{50}$

\section{FINDINGS AND CONCLUSIONS AS A BASIS FOR REVIEW}

While the amount of procedural litigation arising out of the operation of the statutes relating to findings of fact and of law has been very large, the courts have had surprisingly little to say regarding their purpose. Apparently judges have been none too clear in their minds as to what useful service was performed by the system of findings. Interpretation of procedural rules would seem to require constant reference to the objects to be attained, but such references have been conspicuously absent in connection with these provisions.

Judge Hand, in an early New York case already cited, ${ }^{57}$ could offer no better explanation than that the findings were useful to enable parties to protect their rights in case of future suits. The Supreme Court of Wisconsin suggested that their purpose was to aid the parties by showing what was really adjudicated,,$^{58}$ and the Supreme Court of Washington thought they were designed to protect the trial judge by enabling him to place upon the record his view of the facts and the law in clear and unmistakable form. ${ }^{59}$ Such explanations are inadequate.

On the other hand, there have been suggestions that findings were intended to facilitate review, by offering to parties a means of bringing up

${ }^{56} 235$ Mass. 482, 494, 126 N.E. 84r, 842-43 (1920).

57 Gilchrist v. Stevenson, 7 How. Pr. (N.Y.) 273 (I852).

${ }^{88}$ Dietz v. City of Neenah, 9I Wis. 422,64 N.W. 299,65 N.W. 500 (1895).

59 Bard v. Keeb, I Wash. 370, 375 (1890). 
the case without the trouble and expense of a bill of exceptions, ${ }^{60}$ and by helping the reviewing court to understand the theory and the conclusions of the trial judge. ${ }^{6}$ During the short period when findings were provided for in Mississippi, it was pointed out by the Supreme Court of that state in Bloom v. Helm that "the statute requires findings only when requested by one of the parties 'with a view to except to the decision of the court,'" and that its object was "to enable the appellate court to see what view was taken of the law, and what of the facts."

The first of these suggestions, as to the purpose of findings in a system of appellate review, relates to a comparatively unimportant matter, for a meritorious appeal is rarely based upon the sole question whether findings, properly and adequately embodying the proof, are sufficient in law to support the judgment. Appeals based on the findings alone as a part of the judgment roll are more likely to be vexatious appeals raising questions as to the technical sufficiency of the findings.

But the second suggestion, that findings facilitate the work of the reviewing court in an ordinary appeal, by clarifying the issues, has substantial merit.

It seems probably that this was the purpose for which findings were first required in New York. The code of 1849 contained no provision for findings under any circumstances. A "decision" was merely to be "given in writing by the court, and filed with the clerk within twenty days after the court at which the trial took place."63 By the next section it was provided that exception could be taken to the decision and

either party desiring a review upon the evidence appearing on the trial, either of the questions of fact or of law, may at any time within ten days after notice of the judgment,.... [make a case containing so much of the evidence as may be material to the question to be raised. The case shall be settled according to the existing practice.] $]^{64}$

This section was amended in $185^{2}$ by substituting for the portion inclosed in brackets the following:

Or within such time as may be prescribed by the rules of the court, make a case or exceptions in like manner as upon a trial by jury, except that the judge in settling the case must briefly specify the facts found by him, and his conclusions of law.6s

As so drawn the statute provided a simple and direct method of employing findings for the purpose of review without injecting them, as a

${ }^{60}$ Western Dry Goods Co. v. Hamilton, 86 Wash. 478, I5० Pac. II7I (I915).

${ }_{6 x}$ Bard v. Keeb, I Wash. 370, 375 (I89o); Dietz v. City of Neenah, 9 I Wis. 422, 64 N.W. 299,65 N.W. 500 (1895).

${ }_{63}^{63}$ Miss. 21 (I876). $\quad{ }^{63}$ Sec. $267 . \quad{ }^{6}$ Sec. $268 . \quad{ }^{6}$ Italics added. 
complicating factor, into the proceedings for obtaining a judgment in the trial court. No findings were required in any case unless and until an appeal was taken, and they were then made and settled by the judge for the sole purpose of facilitating the review.

Unfortunately the power of the common law tradition was too great to permit this admirable plan to become firmly established in the procedure of New York. The alluring resemblance between special findings and the common law special verdict seems to have irresistibly forced the findings into the record of the trial court. In I86o section 267 of the code was amended so as to require the decision in every case to contain "a statement of the facts found, and the conclusions of law separately." That apparently set the pattern for American legislation.

One group of states has a form of statute which suggests that special findings are to be employed only for the purpose of review. The provision is that "it shall not be necessary for the court to state its finding except, generally, for the plaintiff or defendant, unless one of the parties reguests $i$, with a view to excepting to the decision of the court, upon the questions of law involved in the trial, in which case the court shall state in writing the facts found separately from the conclusions of law." Indiana, Kentucky, Mississippi under the Code of $187 \mathrm{I}{ }^{66}$ Missouri, Nebraska, Ohio, Oklahoma, and Wyoming have substantially this provision.

It would seem from the language employed in this form of statute that general findings, express or implied, were to be deemed sufficient for the trial court record, as a foundation for the judgment, but that in case of review, since exceptions to general findings would give little indication of the precise points to be urged on appeal, such exceptions should be made more definite and certain by setting forth in the appellate record the special facts and conclusions upon which the general finding was based. And if this were the proper interpretation it would follow that judgment might properly be entered on the general finding and that afterward special findings might be drawn up in preparing the case for appeal.

This view is precluded in Indiana by the addition, at the end of the provision above quoted, of the following clause- "and judgment shall be entered accordingly." But it is not thus precluded in the other states of this group, because none of the others have this clause, and yet only one of those courts seems ever to have held that the special findings could be deferred until it appeared that they were necessary for an appeal.

In The Albin Co. v. Ellinger $\&$ Co. the Court of Appeals of Kentucky held that it was not necessary to make special findings before judgment,

${ }^{6}$ Sec. 650 . 
but they could properly be made at the request of the losing party as a basis for a motion for a new trial or appeal after he knew, from the fact that judgment was rendered against him, that he would need them for that purpose. The court, after quoting the code provision, said:

It seems to us unreasonable to require a party to make such request before he had any evidence or reason to believe that he would desire to except to the decision of the court. The presumption is that each party would be expecting a favorable decision, and the reasonable inference from such a request would be that he was at least apprehensive of an adverse decision, else he would not be preparing in advance to except. It seems clear to us that the clear interpretation or meaning of the code, supra, is that a party need not ask for such separation until after the judgment is rendered, for until then he could not know, and should not be required to anticipate an adverse decision, or one to which he might desire to except. ${ }^{67}$

The doctrine here announced accords exactly with the procedure relating to findings introduced in New York in I852. In effect it transfers the use of findings from the field of trial practice to the field of appellate review. By so doing, it eliminates, in the trial court, all the useless burdens resulting from the substitution of special findings for the common law special verdict, and it preserves, in the appellate court, whatever advantages result from a judicial specification of the precise matters of law and fact which are challenged on appeal. ${ }^{68}$

${ }^{67}$ ro3 Ky. 240, 250, 44 S.W. 655, 657 (I898).

${ }^{68}$ See comments on the use of findings by Judge W. Calvin Chesnut, Analysis of Proposed New Federal Rules of Civil Procedure, 22 A.B.A.J. 533 (Aug. 1936). 